\title{
Water Absorption and HEMA Release of Resin-Modified Glass-lonomers
}

Nilufer Celebi Beriat ${ }^{2}$

Dilek Nalbant ${ }^{b}$

\section{ABSTRACT}

Objectives: The aim of this study was to evaluate the water absorption and the amount of hydroxyethyl metacrylate (HEMA) level released from various resin modified glass ionomer cements.

Methods: Advance, Vitremer and Protec-Cem resin modified glass ionomer cements were used to evaluate the HEMA release. Ten specimens were fabricated from each cement in $10 \times 1 \mathrm{~mm}$ height. Thirty specimens were immersed in glass containers filled with $20 \mathrm{ml}$ deionized water. $1 \mathrm{ml}$ solution was taken from the container at 10 minutes, 1 hour, 24 hour and 7 days intervals from each group and analyzed with high performance liquid chromatography (HPLC) machine and the results are presented in ppm. The data were subjected to Kruskal-Wallis, Mann-Whitney and Wilcoxon tests at a 0.05 significance level.

Results: At all time intervals Vitremer showed highest HEMA release ( 10 min: 54.2 ppm; 1 h: 86.8 ppm; $24 \mathrm{~h}: 93.4 \mathrm{ppm})(\mathrm{P}=0.0001)$. At the end of 10 minutes and first hour, following Vitremer, HEMA release was highest for Protec-Cem (10 min: 14.8 ppm; 1 h: 23.6 ppm) and then Advance (10 min: 5.5 ppm; $1 \mathrm{~h}: 18.8 \mathrm{ppm})(\mathrm{P}<.05)$. Water absorption tests were performed according to the specifications of ISO 4049. Water absorption was highest for Vitremer and lowest for the Protec-Cem and the difference among cement groups was significant $(P<.005)$.

Conclusions: Vitremer showed the highest HEMA release and water absorption values and Protec-Cem showed the lowest values. HEMA release by time was significant for Advance cement. This release may be relevant both to the risk of adverse pulpal responses in patients and to the risk of allergy in patients and dental personnel. (Eur J Dent 2009;3:267-272)

Key words: Water absorption; HEMA; Resin-modified glass-ionomers.

a School of Dental Technology, Hacettepe University. Ankara, Turkey

b Department of Prosthodontics, Faculty of Dentistry, Gazi University, Ankara, Turkey.

- Corresponding author: Nilufer Celebi Beriat School of Dental Technology,

Hacettepe University, Ankara, Turkey.

Phone: +90 3123051587

E-mail: nberiatahotmail.com

\section{INTRODUCTION}

Wilson and Kent introduced glass-ionomer cements to the dental profession in 1972. Conventional glass-ionomer cements set by an acid-base reaction between the ion-leachable glass and the polyalkenoic acid their main advantages are adhesion to tooth structure, fluoride release and good biocompatibility. Unfortunately, conventional 
glass-ionomer cements have low tensile strength and fracture toughness, they are susceptible to attack by moisture during the initial setting period and they have short working time, long setting and maturation time. ${ }^{1-7}$

Resin-modified glass-ionomer cements have been developed to overcome such problems. They were used originally as restorative materials and then as luting agents. ${ }^{1}$ The composition of resinmodified glass-ionomer is variable but typically it consist vinyl-modified polyalkenoic acid, a water soluble methacrylate such as hydroxyethyl methacrylate, and ion-leachable glass and water. ${ }^{8-10}$ Resin-modified glass-ionomer cements have a setting reaction including an acid-base reaction as conventional glass-ionomer cements but also a polymerization reaction involving unsaturated side-chains on the modified polyacid take place. In some resin modified glass-ionomer cements the networks of polyacid and ionically cross-linked polyalkenoate chains provides the structural integrity of the cement, as seen in Fuji II LC and Photac-Fil. In Vitremer the two networks are, in addition, cross linked through pendant methacrylate groups on the polyalkenoate molecules. ${ }^{1,11}$ Advantages of these resin-modified glass-ionomer cements include a shortened setting time, decreased early moisture sensitivity, extended working time and greater strength properties compared to conventional glass-ionomer cements. In vitro studies indicate that fluoride release of resin-modified glass-ionomer and conventional glass ionomer cements are same. Several in vitro studies have demonstrated that most of the commercial resin-modified glass-ionomer cements present more intense cytotoxic effects than conventional glass-ionomer cements. ${ }^{8}$ The high cytotoxicity of resin-modified glass-ionomer cements is probably caused by leachable resin components, such as 2-hydroxyethyl methacrylate, which has frequently been added to their chemical composition. Leached residual monomer can easily diffuse through the dentinal tubules due to its hydrophilic property and low molecular weight, and reach dental pulp cells., ${ }^{3,11-19}$

A significant disadvantage of resin ionomer is the hydrophilic nature of poly- hydroxyethyl methacrylate, which results in increased water absorption and subsequent plasticity and hygroscopic expansion. ${ }^{12,20,21}$
The purpose of this study was to evaluate the water absorption and the amount of hydroxyethyl metacrylate released from different modified glass ionomer cements. The null hypothesis tested was: the amount of monomer release does not influence the water absorption of resin modified glass ionomer cements.

\section{MATERIALS AND METHODS}

Three resin modified glass ionomer luting cements were used; Advance (Caulk/Dentsply Inc. USA), Vitremer (3M Dental Products, USA), Protec-Cem (R\&D Vivadent, Liechtenstein). All materials consists at least $18-20 \%$ HEMA.

\section{Examination of HEMA release}

Ten specimens were made from each material. All cements were mixed according to their manufacturers' instructions at the recommended powder: liquid ratio by weight. The components were mixed on the supplied mixing pads by using a stainless steel mixing spatula at room temperature. The mixed paste was then packed into a stainless steel ring mold $(10 \times 1 \mathrm{~mm})$ placed on a glass side. A second glass side was placed on top of the mold and by applying firm hand pressure excess material was expelled via the split. Specimens were cured for the time recommended in their manufacturers' instructions for clinical use. After curing the specimens were allowed to mature in an incubator at $37^{\circ} \mathrm{C}$ for an hour. Then all specimens were put in $20 \mathrm{ml}$ deionized water and sealed with parafilm. Specimens were stored at room temperature $\left(23^{\circ} \pm 2^{\circ} \mathrm{C}\right)$ for various time intervals of ten minutes, an hour, one day and seven days separately. At the end of each time interval, $1 \mathrm{~mL}$ of the solution in the vials were transferred into new $5.0 \mathrm{~mL}$ vials using a 200-1000 $\mu \mathrm{L}$ automatic micropipette (VWR, Wheaton Instruments, Millville, NJ). The storage vials refilled with fresh distilled water to gain again $20 \mathrm{ml}$ of storage media. Again the caps were sealed with parafilm. The residual HEMA content of each specimen were determined for all storage intervals by using high performance liquid chromatography machine.

For quantification of the residual HEMA, a Waters HPLC, equipped with 600E Multisolvent Delivery System, Model U6K Universal Liquid Chromatograph Injector and Waters 484 SingleChannel Tunable UV/Visible Detector (Waters Di- 
vision, Millipore Co., Milford, MA), tuned to $215 \mathrm{~nm}$ was used. A Resolve C18 guard column preceded the Resolve C18 (5 $\mu \mathrm{m}, 150 \times 3.9 \mathrm{~mm}$ ) reversedphase analytical column. Chromatograms were evaluated, processed, and stored by the use of Waters Millennium chromatography manager software program (Waters Corp., Milford, MA).

Four-point calibration curve was constructed by plotting peak areas against concentrations (external standard method) at a flow rate of $1.7 \mathrm{~mL}$ min $^{-1}$ of mobile phase $115 \%$ methanol, $85 \%$ deionized water) under isocratic conditions. HPLC grade methanol (J.T. Baker, Philipsburg, NJ) was used. The chromatograph and detector were calibrated using HEMA solutions of known concentration (10.7, 50 and 107 ppm). There was a linear relationship between detector response and HEMA concentration. The experimental set-up was calibrated prior to use. Peak identity in the samples was determined by comparing the retention times with that of HEMA $(7 \mathrm{~min})$ reference standard. Triplicate injections were made from both standard and specimen solutions. Limit of detection for HEMA was estimated from the break in the slope of standard calibration curve. The amount of released HEMA was presented in ppm. The results were analyzed by using Kruskal-Wallis, MannWhitney and Wilcoxon tests. Significance level was set at 0.05 for statistical analysis.

\section{Examination of water absorption}

All materials were manipulated according to manufacturers' instructions. Ten specimens were made from each cement type and treated as specified by International Standard ISO 4049: 1994. A stainless steel split ring mold was fabricated for the preparation of specimen discs, which were $15 \mathrm{~mm}$ in diameter and $1.0 \mathrm{~mm}$ thick. The mold was first slightly over filled with material and then sandwiched between two glass plates to extrude excess material. After 10 minutes of setting time, the specimens were removed from the molds. The specimens were then transferred to a desiccator maintained at $37 \pm 1^{\circ} \mathrm{C}$. After 24 hours the specimens were removed and stored in a desiccator maintained at $23 \pm 1^{\circ} \mathrm{C}$ for $1 \mathrm{~h}$ and then weighed to an accuracy $\pm 0.2 \mathrm{mg}$. This cycle was repeated until a constant mass was obtained. The samples were weighed in an electronic balance analyzer (Mettler A J150, Switzerland) (M1). Deionized water was added into the glasses and they were stored in an incubator under $37 \pm 1^{\circ} \mathrm{C}$ for 7 days. At the end of the seventh day they were dried with air spray for one minute and they were weighed (M2). Then the samples were placed in a desiccator at $23 \pm 1^{\circ} \mathrm{C}$ for 1 hour, and they were again weighed (M3).

Absorption was calculated according to the formula ${ }^{21}$

$W s p=\frac{M 2-M 3}{V}$

Wsp: Absorption of test material $\left(\mu \mathrm{g} / \mathrm{mm}^{3}\right)$

$\mathrm{V}$ : Volume of cylinder $\left(\mathrm{mm}^{3}\right)$

M1, M2, and M3 values was calculated as microgram $(\mu \mathrm{g})$ and the volume of the cylinder as cubic millimeter $\left(\mathrm{mm}^{3}\right)$, and the results were calculated as $\mu \mathrm{g} / \mathrm{mm}^{3}$.

The base statistics for Advance, Vitremer and Protec-Cem groups, which were tested in the study, are presented in Table 1. The data were evaluated with Kruskal-Wallis variance analysis and Mann-Whitney $U$ tests and also Spearman's correlation coefficient was calculated.

\section{RESULTS}

The mean values and standard deviations of HEMA release were presented in Figure 1. At all time intervals Vitremer showed highest HEMA release $(P=0.0001)$. At the end of 10 minutes and first hour, HEMA release was highest for Protec-Cem and then Advance, following Vitremer $(P<.05)$. At the end of first and seventh day, HEMA release was highest for Advance and then Protec-Cem, following Vitremer $(P=0.004)$. Wilcoxon paired two sample test was undertaken to analyze the HEMA release dependency on time. After the first hour the increase at HEMA release was not significant for Vitremer and Protec-Cem ( $P<.05)$. For Advance cement the increase at HEMA release was not significant after the first day ( $P=0.005)$.

Water absorption was highest for Vitremer and lowest for the Protec-Cem and the difference among cement groups was significant ( $P=0.005)$ (Figure 2). There was a significant correlation between water absorption and monomer release (Spearman's $r=0.434, P<.05$ )

\section{DISCUSSION}

The null hypothesis tested which was the amount of monomer release does not influence the water absorption of resin modified glass iono- 
mer cements, was rejected because of the significant correlation between monomer release and water absorption. Water absorption by resin based composite materials is a diffusion controlled process, and the water uptake occurs largely in the resin matrix. The water absorbed by the polymer matrix could cause filler matrix debonding or even hydrolytic degradation of the fillers, and may affect composite materials by reducing their mechanical properties. The hydrolytic degradation is a result of either the breaking of chemical bonds in the resin or softening through the plasticizing action of water. When resin samples are immersed in water, some of the components such as unreacted monomers dissolve and are leached out of the samples. In this study Vitremer was the most water absorbing material as well as most HEMA releasing material. Also Protect-Cem was the least water absorbing and least HEMA releasing material.

Glass ionomer cements gained popularity because of their properties such as biocompatibility, fluoride release and prevention of caries. However they are not perfect and have some drawbacks such as short working time, long setting time, sen- sitivity to humidity. Resin modified glass ionomer cements was developed to resolve these problems by adding resin (such as hydroxyethyl metacrylate) to conventional glass ionomer cement content. Although resin may have some adverse effect on some good properties of conventional glass ionomer cements such as biocompatibility, especially if sufficient concentrations of the components diffuse through dentin to the pulp space, adhesion of resin modified glass ionomer cements is enhanced because of their resin content. ${ }^{15}$

Gerzina et $\mathrm{al}^{14}$ investigated the release of monomers and their diffusion to dentin of various resin bonding agents and resin composite combinations. They proved HEMA and TEGDMA release from the restorative material and their diffusion to pulp space. They reported that HEMA was a hydrophilic material that enhances the micromechanical and chemical adhesion to dentin.

Resins such as HEMA and TEGDMA can have direct toxic effects on the pulpal cells in vivo and can cause allergic responses in patients and dental workers. The studies regarding the release of HEMA from resin modified glass ionomer cements used different sample dimensions that makes dif-

Table 1. Basic statistical data of HEMA release and water absorption of all materials used. Superscript letters indicates statistical differences.

\begin{tabular}{lccccc}
\hline & \multicolumn{4}{c}{ HEMA release $(\mathrm{ppm})$} & Water \\
& $10 \mathrm{~min}$ & 1 hour & 24 hour & $\mathbf{7}$ days & Absorption $\left(\mu \mathrm{g} / \mathrm{mm}^{3}\right)$ \\
\hline Vitremer & $54.2(5.66)^{\mathrm{a}}$ & $86.8(12.64)^{\mathrm{a}}$ & $93.4(10.42)^{\mathrm{a}}$ & $90.1(14.41)^{\mathrm{a}}$ & $188.9(22.54)^{\mathrm{a}}$ \\
Advance & $5.5(2.07)^{\mathrm{b}}$ & $18.8(3.87)^{\mathrm{b}}$ & $34.6(5.49)^{\mathrm{b}}$ & $37.1(6.40)^{\mathrm{b}}$ & $132.8(19.77)^{\mathrm{b}}$ \\
Protec-Cem & $14.8(9.07)^{\mathrm{c}}$ & $23.6(4.03)^{\mathrm{c}}$ & $27.0(5.36)^{\mathrm{c}}$ & $28.6(3.85)^{\mathrm{c}}$ & $130.4(71.49)^{\mathrm{b}}$ \\
\hline
\end{tabular}

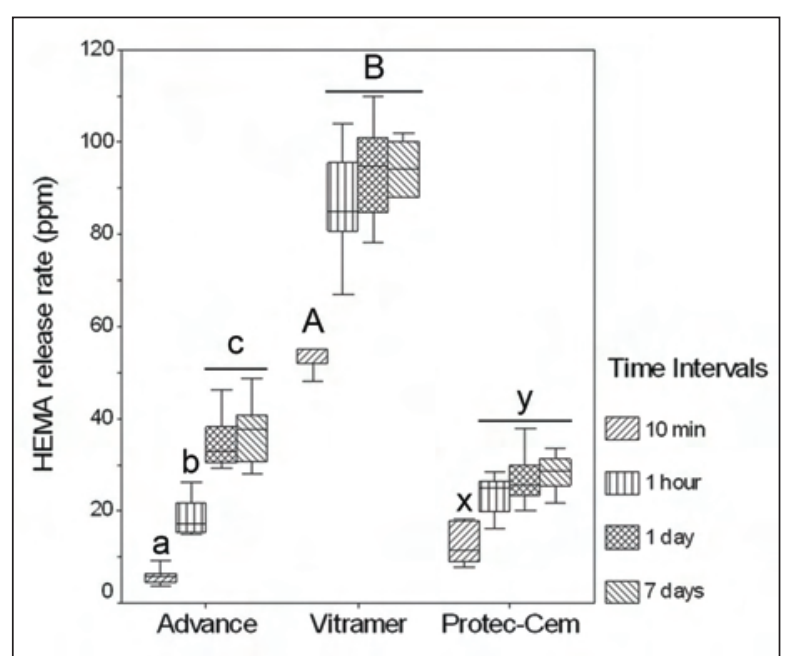

Figure 1. HEMA release rates of all cements by time. Letters indicate statistical difference.

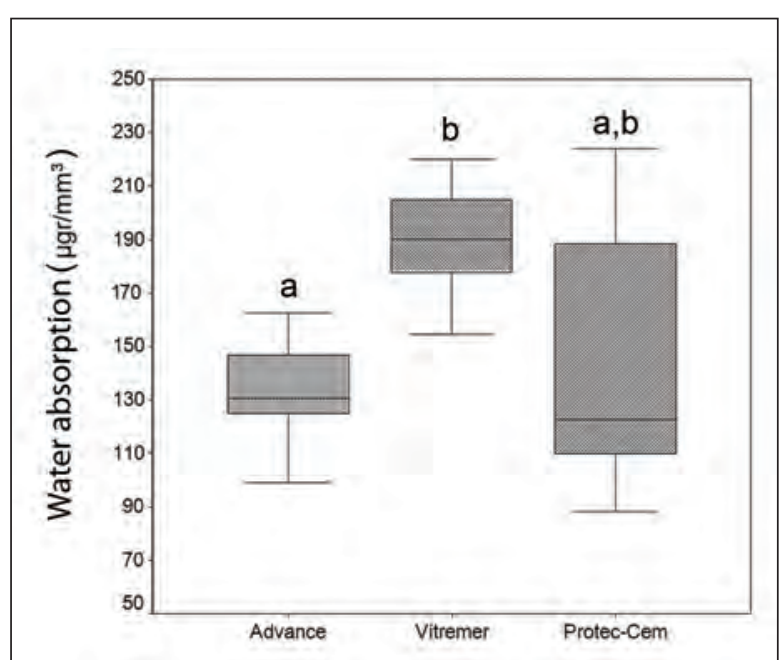

Figure 2. Water absorption of all cements. Letters indicate statistical difference. 
ficult to compare the results. In order to overcome this problem in this study, the samples were fabricated according to the requirements of ADA 9.

High performance liquid chromatography has been used previously in dental research and has been proven to be a powerful analytical technique that can analyze dental polymers, including residual monomers, composites and various other dental materials. In this study HPLC was used to detect HEMA release from the samples. ${ }^{22} 15 \%$ water: $85 \%$ methanol media was used in this study. In some studies water or water: ethanol solutions were used as elution media, and it was reported that there is a correlation between the amount of ethanol in the media and the amount of detected monomer. The elution media were not changed between measurements to enhance the accuracy and avoid possible errors. This methodological aspect was used in other studies although one study reported that changing the media between measurements allowed a better examination. One of the drawbacks of the study was extent of reaction was not investigated. It should be noted that if the materials did not polymerized adequately then more monomers would be available for elution. Further studies were needed to investigate and compare the degree of conversion and monomer release.

There was a significant increase in HEMA release by time from 10 minutes to first hour for all cements however this increase continued from first hour to the end of 24 hours for only Advance cement. There was not a significant increase in HEMA release by time from the end of 24 hours to the end of 7 days for all cements. This rapid release of HEMA was reported in other studies. Mazzaoui et $\mathrm{al}^{23}$ reported that the greatest release of monomers occurred in the first day.

In this study, samples were prepared as specified by the International Standard ISO 4049 for water absorption test. There is a significant difference among the cement groups for water absorption. Iwami et $\mathrm{al}^{24}$ reported that water absorption of resin modified glass ionomer cements have a higher amount of water absorption when the compared with polyacid modified glass ionomer cements because of their resin content. In this study a similar result was found between resin release and water absorption.

In concordance with the present study result
Yap et $a^{21}$ showed similar water absoption values for Vitremer even if they used a chemically polymerized version of the material, because water absorption mainly depends on the resin compositions. Also Toledano et $\mathrm{al}^{25}$ proposed that hydophilic consituents such as HEMA clearly inceased the water absorption values and in their study Vitremer was also showed the higher water absorption values.

\section{CONCLUSIONS}

Within the limitations of this in vitro study the following conclusions were drawn;

- There was a significant correlation between HEMA release and water absorption.

- Vitremer showed the highest HEMA release and water absorption values and Protec-Cem showed the lowest values.

- HEMA release by time was significant for Advance cement.

- It is possible that relatively high and rapid release of HEMA may have direct, toxic effects on pulpal cells if the remaining dentin is thin. HEMA from resin modified glass ionomer cements may also pose an allergic risk to dental workers and also, possibly, to patients.

\section{REFERENCES}

1. Attin T, Vataschki M, Hellwig E. Properties of resin-modified glass-ionomer restorative materials and two polyacid-modified resin composite materials. Quintessence Int 1996;27:203-209.

2. Bell RB, Barkmeier WW. Glass-ionomer restoratives and liners: shear bond strength to dentin. $J$ Esthet Dent 1994;6:129-134

3. Croll TP, Killian CM, Helpin ML. A restorative dentistry renaissance for children: light-hardened glass ionomer/ resin cement. ASDC J Dent Child 1993;60:89-94.

4. de Gee AJ, Leloup G, Werner A, Vreven J, Davidson CL. Structural integrity of resin-modified glass ionomers as affected by the delay or omission of light activation. $J$ Dent Res 1998;77:1658-1663.

5. Kerby RE, Knobloch L, Thakur A. Strength properties of visible-light-cured resin-modified glass-ionomer cements. Oper Dent 1997;22:79-83.

6. Leevailoj C, Platt JA, Cochran MA, Moore BK. In vitro study of fracture incidence and compressive fracture load of allceramic crowns cemented with resin-modified glass ionomer and other luting agents. J Prosthet Dent 1998;80:699707 
7. Mitchell CA, Douglas WH, Cheng YS. Fracture toughness of conventional, resin-modified glass-ionomer and composite luting cements. Dent Mater 1999;15:7-13.

8. Aranha AM, Giro EM, Souza PP, Hebling J, de Souza Costa CA. Effect of curing regime on the cytotoxicity of resinmodified glass-ionomer lining cements applied to an odontoblast-cell line. Dent Mater 2006;22:864-869.

9. Bertacchini SM, Abate PF, Blank A, Baglieto MF, Macchi $\mathrm{RL}$. Solubility and fluoride release in ionomers and compomers. Quintessence Int 1999;30:193-197.

10. Nakabayashi N, Takarada K. Effect of HEMA on bonding to dentin. Dent Mater 1992;8:125-130.

11. Allen EP, Bayne SC, Becker IM, Donovan TE, Hume WR, Kois JC. Annual review of selected dental literature: report of the Committee on Scientific Investigation of the American Academy of Restorative Dentistry. J Prosthet Dent 1999;82:27-66.

12. Bouillaguet S, Wataha JC, Hanks CT, Ciucchi B, Holz J. In vitro cytotoxicity and dentin permeability of HEMA. $J$ Endod $1996 ; 22: 244-248$.

13. Donovan TE, Cho GC. Contemporary evaluation of dental cements. Compend Contin Educ Dent 1999;20:197-199, 202208, 10 passim; quiz 20.

14. Gerzina TM, Hume WR. Diffusion of monomers from bonding resin-resin composite combinations through dentine in vitro. J Dent 1996;24:125-128.

15. Hamid A, Okamoto A, Iwaku M, Hume WR. Component release from light-activated glass ionomer and compomer cements. J Oral Rehabil 1998;25:94-99.

16. Kan KC, Messer LB, Messer HH. Variability in cytotoxicity and fluoride release of resin-modified glass-ionomer cements. J Dent Res 1997;76:1502-1507.

17. Morand JM, Jonas P. Resin-modified glass-ionomer cement restoration of posterior teeth with proximal carious lesions. Quintessence Int 1995;26:389-394.

18. Palmer G, Anstice HM, Pearson GJ. The effect of curing regime on the release of hydroxyethyl methacrylate (HEMA) from resin-modified glass-ionomer cements. $J$ Dent 1999;27:303-311.

19. Souza PP, Aranha AM, Hebling J, Giro EM, Costa CA. In vitro cytotoxicity and in vivo biocompatibility of contemporary resin-modified glass-ionomer cements. Dent Mater 2006;22:838-844.

20. Pashley EL, Zhang Y, Lockwood PE, Rueggeberg FA, Pashley $\mathrm{DH}$. Effects of HEMA on water evaporation from waterHEMA mixtures. Dent Mater 1998;14:6-10.

21. Yap A, Lee CM. Water sorption and solubility of resin-modified polyalkenoate cements. J Oral Rehabil 1997;24:310314.
22. Silikas N, Watts DC. High pressure liquid chromatography of dentin primers and bonding agents. Dent Mater 2000;16:81-88.

23. Mazzaoui SA, Burrow MF, Tyas MJ, Rooney FR, Capon RJ. Long-term quantification of the release of monomers from dental resin composites and a resin-modified glass ionomer cement. J Biomed Mater Res 2002;63:299-305.

24. Iwami Y, Yamamoto H, Sato W, Kawai K, Torii M, Ebisu S. Weight change of various light-cured restorative materials after water immersion. Oper Dent 1998;23:132-137.

25. Toledano M, Osorio R, Osorio E, Fuentes V, Prati C, Garci, et al. Sorption and solubility of resin-based restorative dental materials. J Dent 2003;31:43-50. 